Journal of Engineering and Applied Sciences 14 (8): 2450-2455, 2019

ISSN: 1816-949X

(C) Medwell Journals, 2019

\title{
A Study on the Resonance Dispersion of Candlelight According to the Change of Sound Component
}

\author{
${ }^{1}$ Bong-Young Kim, ${ }^{1}$ Uk-Jin Song, ${ }^{2}$ Seong-Geon Baeand and ${ }^{1}$ Myung-Jin Bae \\ ${ }^{1}$ Department of Information and Telecommunication Engineering, Soongsil University, \\ Sangdo-ro, Dongjak-gu, 369 Seoul, Korea \\ ${ }^{2}$ School of Software Application, Kangnam University, Gyunggi-do, Korea
}

\begin{abstract}
Fire is a very important thing in human civilization. However, fire causes enormous damage to humans by conflagration. Due to the development of society, the fire protection environment has changed and more efficient fire protection technology is needed and sound fire extinguisher can be an alternative. Sound fire extinguisher has the principle that the fire is turned off by using various phenomena caused by the resonance of the sound component. Sound fire extinguisher can easily suppress the flame by supplying a sound component appropriate to the combustion characteristics of the flame. In this study, a low frequency speaker was used to supply different sound components to the candlelight and the resonance dispersion size of the candlelight was measured. Through these experiments, we tried to identify a sound component that can be easily turned off by candlelight. Experimental results show that although, the resonance is somewhat different depending on the position of the candlelight, the candlelight is dispersed by resonance at frequencies of about 30,70 and $100 \mathrm{~Hz}$ at most positions. It can be predicted that the candlelight can be easily turned off by resonance at the frequency of harmonics based on about $30 \mathrm{~Hz}$ band.
\end{abstract}

$\underline{\text { Key words: Conflagration, sound fire extinguisher, resonance, sound component, dispersion, frequency }}$

\section{INTRODUCTION}

In Greek mythology, Prometheus, made of earth and water, stole Zeu's stored fire and presented it to humans. Because of this Prometheus taught humans the first civilization and was cursed by Zeus. It is estimated that the era of mankind's use of fire began about 2.6 million years ago to 200,000 years ago. From the time of the Paleolithic era, mankind has used fire for mining, cooking, defense and used tools. In Neolithic times, it was possible to cause direct fire by impact. The fire was accompanied by the beginning of human civilization. In modern times, fire has become an inseparable part of society, economy, culture, military and energy (Kim, 2011). However, fire is a subject of fear for humans. Conflagration gives man very great damage and despair. In 2003, a conflagration of Daegu subway station in Korea, 192 people were killed. In addition, various large-scale conflagration disasters occurred and in December, 2017, the Jecheon conflagration disaster in Chungbuk, Korea caused 29 casualties. With the exception of this large conflagration disaster, Korea has suffered thousands of casualties and hundreds of millions of dollars of property damage every year due to conflagration. Conflagration has been accompanied by human civilization which has begun to use fire and it can be said that it is a companion of humanity that can cause harm at any time. So, we have to be prepared to evolve conflagration when it may come up.

The way to suppress conflagration is to spray water to lower the temperature of the flame or spray a fire extinguishing agent to suppress the supply of oxygen to the flame and turn off the fire. However, there is a need for a fire fighting technique with a new method because the fire safety environment is changing, such as building size and skyscraper, large-scale IT and network resources and buildings certified by information and communication network. In Soongsil University, Korea, Sori sound engineering lab has developed a sound fire extinguisher that effectively works in new fire fighting environment and can effectively improve extinguish efficiency with existing extinguisher equipment (Jung, 2017; Kim, 2017). Sound fire extinguisher is a way to suppress the supply of fuel to the flame due to flame resonance caused by the sound and to suppress the supply of oxygen to the flame which is very different from the extinguish principle of existing extinguisher equipment. Sound fire extinguisher can control various sound components to supply flame

Corresponding Author: Myung-Jin Bae, Information and Telecommunication Engineering, Soongsil University, Sangdo-dong, Dongjak-gu, Seoul, Korea 
(Kyoung-Su et al., 2016; Pak et al., 2015; Eun-Young and Myung-Jin, 2015). Flame can be said to have a different combustion characteristic depending on the nature of the burning material. Sound fire extinguisher can selectively supply sound components suitable for combustion. If the sound fire extinguisher can supply a sound component that resonates with the greatest energy of the flame, we can easily turn off the fire with relatively little sound power.

\section{MATERIALS AND METHODS}

\section{Basic theory and principles}

Resonance: The resonance is a phenomenon in which the amplitude increases significantly when an external force of the same frequency as the natural frequency of the object is received. Even if the frequency of the external force is not the natural frequency of the object, the object has the property to oscillate at the resonance frequency and the resonance of the object is made by the natural frequency and its harmonics. High-rise buildings or bridges may be destroyed by very large abnormal vibration caused by resonance. Resonance is not limited to solids but also in the form of liquids or gases. In the case of liquids have a natural frequency due to the shape of container, dimensions, elasticity, density, etc. In many molecular bonding structures, molecules resonate and bond between structures. If the resonance energy is increased through external force, the change of properties of the molecular structure may affect the decomposition and bonding (Gribbin, 2004).

Combustion: Combustion is a chemical reaction in which a material reacts with oxygen to rapidly heat and light it. To be a combustion, three conditions are required: burning material, high temperature and supply of oxygen. If any of these three conditions are removed, the combustion is stopped. Most of the combustible materials are hydrocarbon compounds containing a large amount of Carbon $(\mathrm{C})$ and Hydrogen $(\mathrm{H})$. In the process of combustion, hydrocarbon compounds react with oxygen to become water and carbon dioxide. The combustion reaction equation of hydrocarbon compounds is Eq. 1:

$$
\mathrm{C}_{\mathrm{m}} \mathrm{H}_{\mathrm{m}}+\mathrm{O}_{2} \Rightarrow \mathrm{CO}_{2}+\mathrm{H}_{2} \mathrm{O}
$$

Principles of sound fire extinguisher: Sound Fire Extinguisher was first released by the Defense Advanced Research Projects Agency (DARPA) and students of George Mason University. However, the sound fire extinguisher introduced at the time suggested that sound affects extinguishment by resonating flame molecules

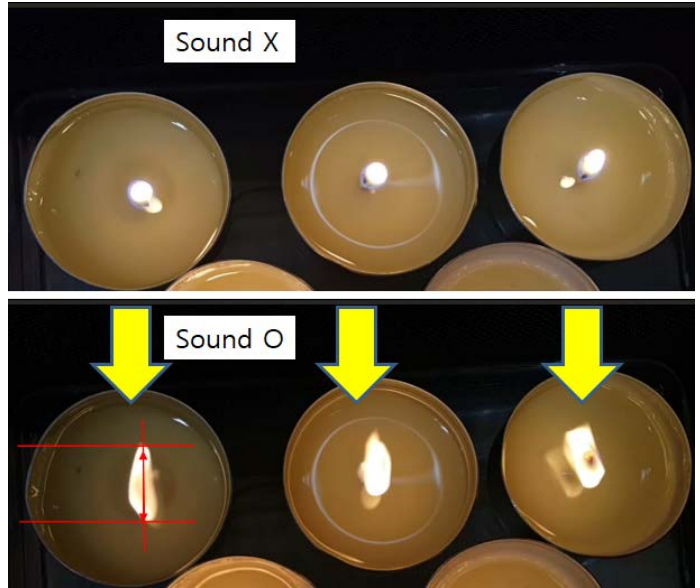

Fig. 1: Flame resonance phenomenon

which is not enough to apply to actual extinguishment (Anthony, 2012). In "Sori Sound Engineering Lab" of Soongsil University, Korea, sound fire extinguisher is actively researching to be used in actual fire fighting environment.

The extinguish principle of sound fire extinguisher utilizes various effects generated by the resonance of flame molecules through the supply of sound. It is "interferes with the bonding of the flame surface and oxygen", "spreads the area of the flame, disperses the heat energy", "lowering the fuel supply to the flame". In addition, "introducing special acoustic lens function to concentrate extinguish ingredient of sound in flame", "principle to extinguish through obstacle according to diffraction ability of low frequency component", "increase of flame area, the principle of inhibiting the combustion by burning in advance", "the principle of suppressing the path where flame is emitted", "the flame retarding principle which suppresses combustion occurrence before conflagration "has been further studied (Yi et al., 2017; Kim et al. 2017, 2018). Figure 1 shows the resonance phenomenon of the flame molecule by the sound component. If the sound is not supplied, the flame will burn and maintain the shape of the arrowhead. However, when the sound is supplied and the flame is resonance, it can be seen that the flame resonance increases as the arrowheads spread sideways. However, in a candlelight experiment when a non-resonant sound such as $200 \mathrm{~Hz}$ is supplied, the flame burns in the same manner as when no sound is supplied.

\section{RESULTS AND DISCUSSION}

The experiment was carried out using a low frequency speaker (Britz AMP BR-5100T) to give a $30 \mathrm{~Hz}-1 \mathrm{kHz}$ sound to the candlelight to measure the 


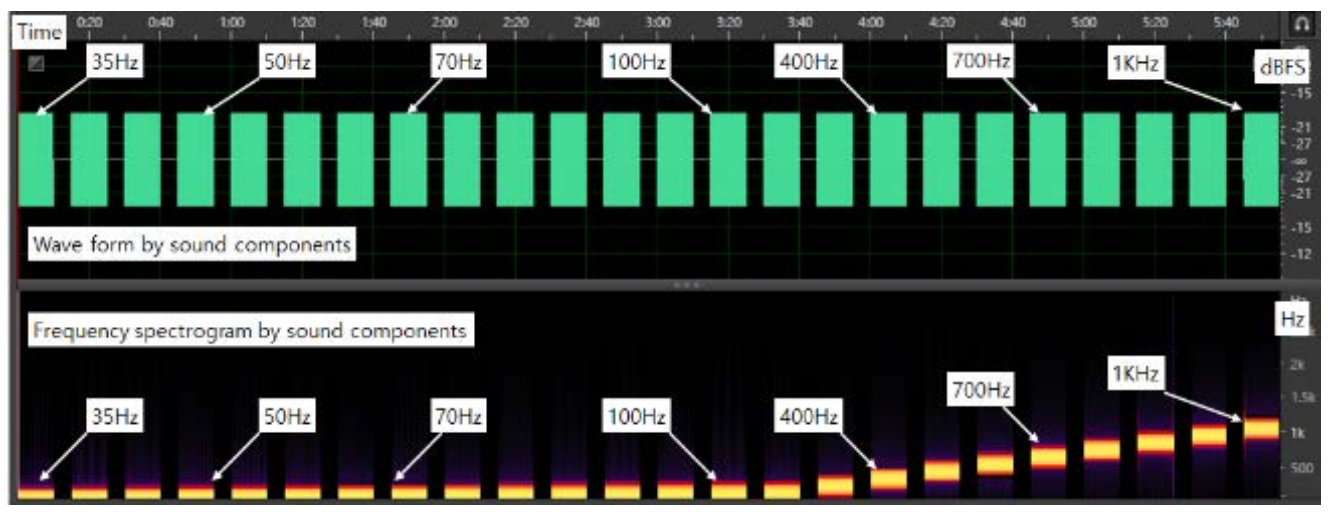

Fig. 2: Sound component supplied to the candlelight (wave from and freqency spectrogram)
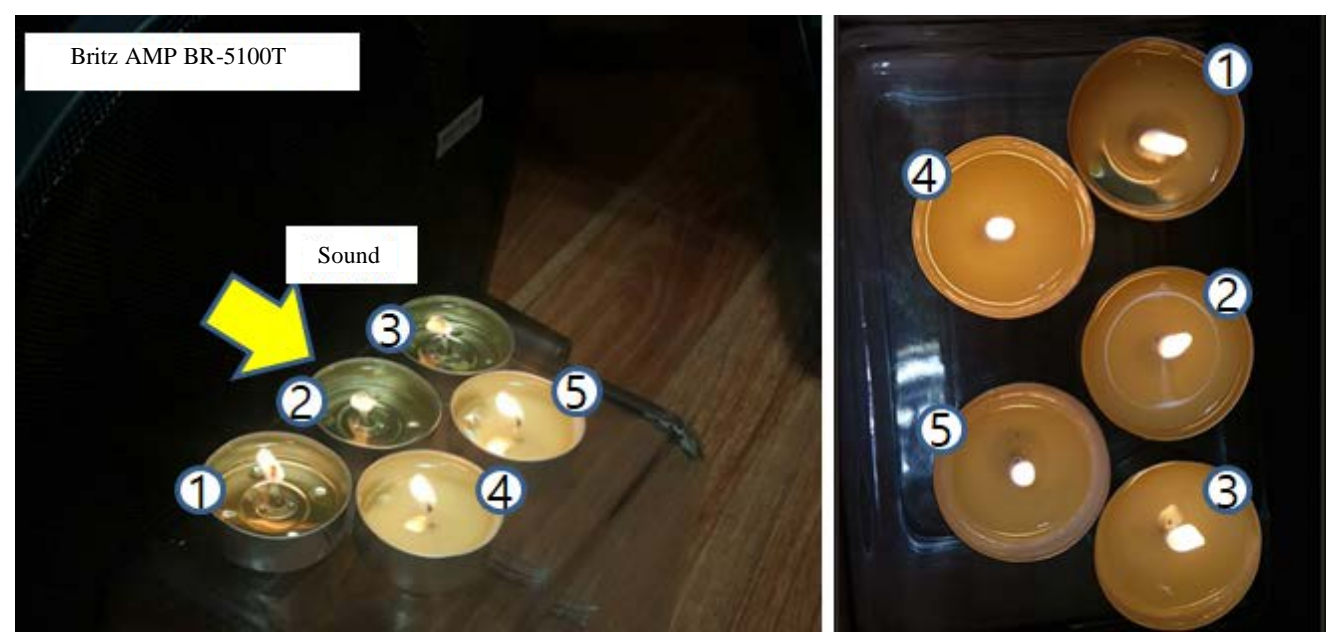

Fig. 3: Experiment secen (measuring the dispersive size of the candlelight)

magnitude of dispersion of the candlelight by resonance. If the sound power provided to the candlelight is as large as the sound fire extinguisher, it will not be able to measure the resonance phenomenon because the candlelight is turned off, so we set the size of the sound to such an extent that the candlelight will not turn off. The sound component provided to the candlelight was increased by $5 \mathrm{~Hz}$ from $30-100 \mathrm{~Hz}$ with each pure tone and the candlelight was provided with an additional $100 \mathrm{~Hz}$ increments from $200 \mathrm{~Hz}-1 \mathrm{kHz}$. The wave form and frequency spectrogram of the sound component provided in the candlelight are shown in Fig. 2. The supply of sound was supplied every $10 \mathrm{sec}$ for each frequency and the time of $5 \mathrm{sec}$ was interrupted between each sound. This allowed the candlelight to recover to its original state and respond to the next frequency component.

In the experiment, five event-type candles with a diameter of about $3.85 \mathrm{~cm}$ were placed in two rows in the center of the low-frequency speaker. A candlelight placed close to the low-frequency speaker was spaced about 6 $\mathrm{cm}$ from the speaker and the farther away candlelight was about $9 \mathrm{~cm}$ away from the speaker. The sound source was played with the Music App. of the Samsung Galaxy Note 4 smart device and the resonance phenomenon of the candlelight was also photographed with the Samsung Galaxy Note 4, a smart device, to measure the dispersion size of the candlelight. In order to minimize the error of the experimental environment, the experiment was prohibited from entering the laboratory during the experiment and the experiment tools were automatically fixed without the intervention of the experimenter during the shooting process. The experimental scene is shown in Fig. 3.

Even if the candlelight is placed close to the speaker, the result of the experiment may be different depending on where the candlelight is placed because the speaker has a sound spreading to the front side. Therefore, the candlelight dispersion size was measured for each of five 


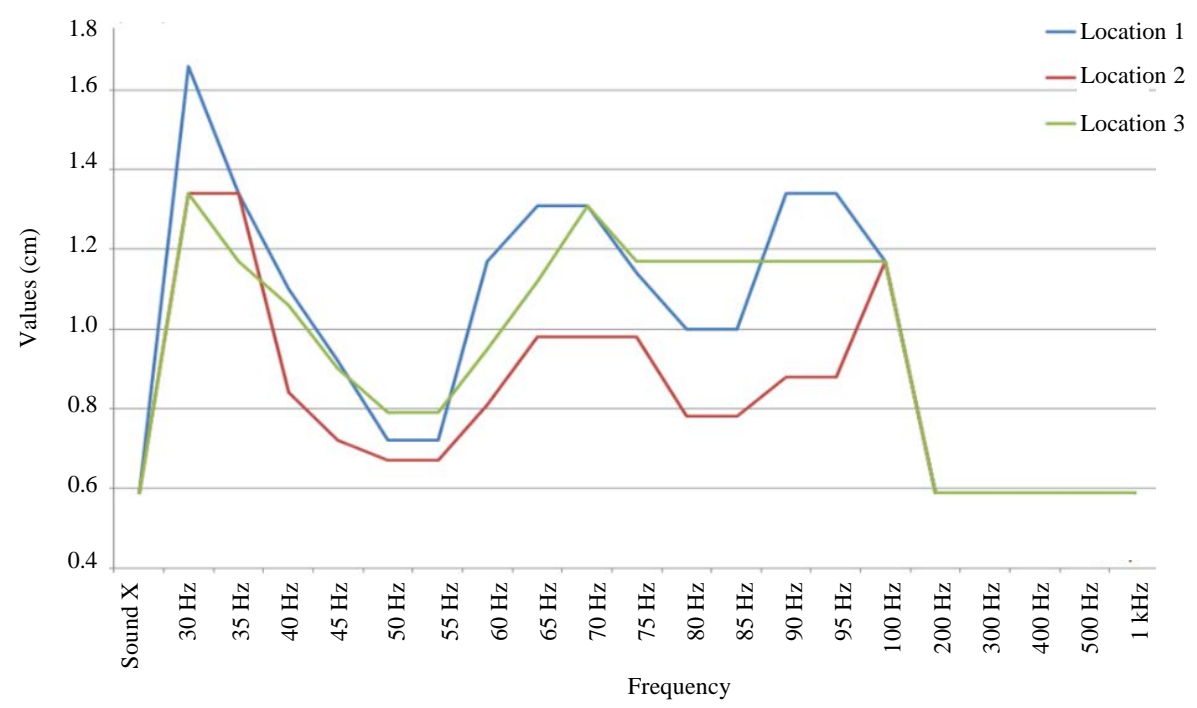

Fig. 4: The dispersive size of the candlelight in the first column

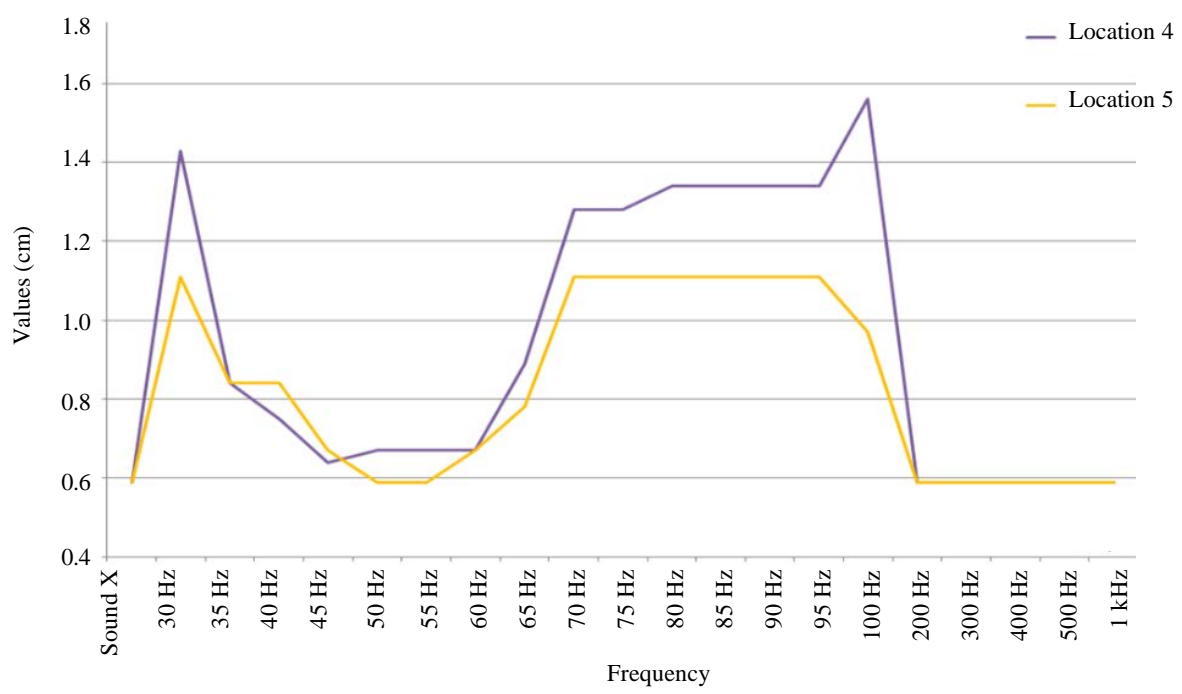

Fig. 5: The dispersive size of the candlelight in the second column

candlelight. The candlelight was somewhat different in size and aspect from the resonance depending on the distance from the speaker. Figure 4 and 5 show the magnitude of the resonance dispersion for each row candlelight.

Figure 4 shows the frequency-dependent resonance dispersion magnitude of the candlelights placed close to the low-frequency speaker. The flame is largely dispersed at $30-35 \mathrm{~Hz}$ and is largely dispersed at $60-70 \mathrm{~Hz}$ and 90-100 Hz. However, in spite of supplying the same size sound, the response of candlelight was low in the other frequency range. Especially, when the frequency exceeded $200 \mathrm{~Hz}$, the candlelight did not respond as it did not hear the sound. Figure 5 shows the frequency-dependent resonance dispersion of a two-row candlelight at about $9 \mathrm{~cm}$ away from a low-frequency speaker. It was largely dispersed at $30 \mathrm{~Hz}$ and largely dispersed over a wide range from $70-100 \mathrm{~Hz}$. However, in the range from $45-60 \mathrm{~Hz}$, the dispersion size was very small and as in Fig. 4, the candlelight did not react at frequencies exceeding $200 \mathrm{~Hz}$.

Comparing Fig. 4 with 5 shows that the position of the candlelight can affected the sound differently. However, it was predicted that the frequencies of 30,70 and $100 \mathrm{~Hz}$ were largely dispersed in most of the candles, so that, the frequency was close to the natural frequency of the candlelight molecule (Boksik, 2015; Cho et al., 2014; Choi, 2009; Demirbas, 2004; Sang-Hwi et al., 2017; Yang, 2010). 


\section{CONCLUSION}

In Greek mythology, Prometheus stole fire from Zeus and presented it to humans, so that, humans became the first civilization. Fire can be said to be the beginning and development of human civilization. Modern civilization without fire is unimaginable. But fire is a very necessary thing for man but it is another name for disaster called conflagration. The occurrence of conflagration causes enormous loss of life and property damage. As the fire-fighting environment changes such as high-rise buildings, more efficient fire-fighting technology is needed. The sound fire extinguisher which has an extinguishing principle different from the conventional way can be an alternative. Sound fire extinguisher turns off the fire by using various phenomena that occur when the sound resonates the flame molecule. Sound fire extinguisher can supply sound components according to combustion characteristics of flame. If a flame provides a sound component with the greatest resonance to the flame, the flame can easily be throttled with the same or a small sound.

In this study, a much smaller sound was supplied to the candlelight instead of the sound fire extinguisher to measure the size of the resonance and dispersion of the candlelight. Through these experiments, we tried to identify the sound component of the resonance of the candlelight. Experimental results showed that the resonance of the candlelight was somewhat different depending on the environment of the experiment and the location of the candlelight. However, the candlelight was largely dispersed in sound components of 30,70 and $100 \mathrm{~Hz}$ at most positions. As a result, the natural frequency of the candlelight is about $30 \mathrm{~Hz}$ and it is found that the resonance is caused by overtone at about 70 and $100 \mathrm{~Hz}$. The environment of this experiment is somewhat distant from conflagration site. However, the resonance characteristics of the flame with the combustion characteristics of the same composition as the candle can be grasped and it can be said that it is a meaningful result to confirm the sound component suitable for the extinguishing of the similar component combustion.

\section{RECOMMENDATIONS}

We hope that this study will contribute to the study of proper fire extinguish method according to the field of conflagration as it was the study to confirm the correlation between sound and extinguishment.

\section{REFERENCES}

Anthony, S., 2012. DARPA creates sound-based fire extinguisher. Ziff Davis, LLC, New York, USA. http://www.extremetech.com/extreme/132859-darpacreates-sound-based-fire-extinguisher.

Boksik, S., 2015. A study on the recycling standard of powder fire extinguisher considering function. Master Thesis, Department of Industrial Engineering, Pusan National University, Busan, South Korea.

Cho, C., K. Kim and C. Jeong, 2014. Fireworks modeling technique based on particle tracking. J. Inst. Electron. Inf. Eng., 51: 102-109.

Choi, S.H., 2009. Improvement of smoke control system for tall buildings. Mag. Soc. Air Conditioning Refrigerating Eng., 38: 26-33.

Demirbas, A., 2004. Combustion characteristics of different biomass fuels. Prog. Energy Combust. Sci., 30: 219-230.

Eun-Young, Y. and B. Myung-Jin, 2015. Study on candlelight extinguish by focused transducer. Acoustical Society of Korea, South Korea.

Eun-Young, Y., S. Uk-Jin and B. Myung-Jin, 2017. A study on the directionality of sound fire extinguisher in electric fire. Convergence Res. Lett. Multimedia Serv. Convergent Art Hum. Sociol., 3: 1449-1452.

Gribbin, J.R., 2004. The Scientists: A History of Science Told through the Lives of its Greatest Inventors. Random House, New York, USA., ISBN:9780812967883, Pages: 646.

Jung, K.M., 2017. Fire Protection Theory. DongHwa Technology Publishing Co., Korea,

Kim, B.Y., E.Y. Yi and M.J. Bae, 2018. A study on the effect of sound component of sound fire extinguisher on extinguish time. Convergence Res. Lett. Multimedia Serv. Convergent Art Human. Sociol., 4: 1905-1908.

Kim, B.Y., M.J. Bae and S.G. Bae, 2017. A study on a suitability of sound fire extinguisher in duct environment. Intl. J. Appl. Eng. Res., 12: 15796-15800.

Kim, I.B., 2017. Fire Suppression Agents. Donghwa Tech Co., Ltd., Korea,

Kim, W.I., 2011. Speak Human from Myth. Badabooks Publishing Co, Ltd., Korea,

Kyoung-Su, Y., P. Sun-Young and B. Myoung-Jin, 2016. A study of acoustic suppression of flame. Conf. Voice Commun. Signal Process. Acoust. Soc. Korea, 32: $170-171$. 
Pak, S.Y., K.S. Yeo and M.J. Bae, 2015. Detection of optimal frequency for candlelight extinguish. Acoustical Society of Korea (ASK), South Korea.

Sang-Hwi, J., P. Hyung-Woo and B. Myung-Jin, 2017. A study on reduction of digestion temperature of sonic fire extinguisher. Convergence Res. Lett. Multimedia Serv. Convergent Art, Hum. Soc., 3: 1457-1460.
Yang, G.G., 2010. [Fire service policy issues for building of safety society (In Korean)]. J. Korean Publ. Police Secur. Stud., 7: 111-135.

Yi, E. Y., U.J. Song and M.J. Bae, 2017. A study on the low frequency amplifier designed for forming a sound pressure. Convergence Res. Lett. Multimedia Serv. Convergent Art Human. Sociol., 3: 1449-1452. 